\title{
Impact of Educational Status and Parity of Mother- in-laws on Practices of Birth Preparedness and Complication Readiness in Banke District
}

\author{
Sushila Acharya, ${ }^{\mathrm{a}, \mathrm{b}}$ Madhusudhan Ghimire, ${ }^{\mathrm{a}, \mathrm{c}}$ Mausami Ghimire ${ }^{\mathrm{a}, \mathrm{c}}$
}

\begin{abstract}
:
Introduction: Pregnancy and childbirth is considered as a physiological process and it is associated with certain risks to the life of mother and newborn baby. Birth-preparedness and complication readiness is a comprehensive strategy to improve maternal and newborn health. This study was done to observe impact of educational status and Parity of mother-in-laws on awareness and practices regarding birth preparedness and complication readiness. Methods: The study was conducted in Banke district. The duration of study was from August 2011 to August 2012. Descriptive crosssectional study was followed. One hundred mothers-in-law were selected through simple random procedure. Semistructure interview schedule was used to collect information. Results: The mean age of mothers-in-law was 52.33 $(S D=8.96)$ years. Majority (82.0\%) mothers-in-law were illiterate with lack of awareness and practice about birth preparedness and complication readiness. Conclusion: Inadequate practices on birth preparedness and complication readiness were prevalent in illiterate mothers-in-laws.
\end{abstract}

Keywords: age • banke district $\bullet$ birth-preparedness/complication • education • readiness practices

\section{INTRODUCTION:}

Pregnancy and childbirth and their consequences are the leading causes of death, disease and disabilities among women of reproductive age in developing countries. It has been argued that nearly three quarters of all neonatal deaths and stillbirth deliveries could be prevented if women were adequately nourished and received appropriate care during pregnancy, childbirth, and postpartum period. ${ }^{1}$

a - Lecturer

b - College of Nursing, Lumbini Medical College, Palpa, Nepal

c - Department of Community Medicine

Lumbini Medical College Teaching Hospital, Palpa, Nepal

Corresponding Author:

Sushma Acharya

e-mail: acharyashusma@yahoo.com

How to cite this article:

Acharya S, Ghimire M, Ghimire M. Impact of educational status and parity of mother-in-laws on practices of birth preparedness and complication readiness in Banke district. Journal of Lumbini Medical College. 2013;1(1):4-6. doi: 10.22502/jlmc.v1i1.2.
Birth-preparedness and complication readiness is a comprehensive strategy to decrease maternal morbidity and mortality. It many include knowledge of danger signs; plan for where to give birth; plan for a birth attendant; plan for transportation and plan for saving money. ${ }^{2}$ Maternal and neonatal health status is poor and it is a serious problem in Nepal, as in other countries of south Asia. There were different program launched through governmental and nongovernmental organizations to reduce the burden of maternal and neonatal death. Despite these entire programs, the burden is still high. ${ }^{3}$ This study was done to observe impact of educational status and parity of mother-in-laws on awareness and practices regarding birth preparedness and complication readiness.

\section{METHODS:}

A cross-sectional descriptive study was used to conduct the study. Cluster random sampling was used to select 100 mothers-in-laws (20 from each 
ward) in wards 1, 2, 7, 8, and 9 of Saigau, Indrapu, Jaispur, Belbhar, and Paraspur village development committee of Banke district respectively. Data were collected through pre-tested interview schedule after got hold of written permission of concerned authorities. Awareness scoring system was used to decide on the level of awareness and was designated inadequate and moderate according to the score. The results were then calculated. Data were analyzed through Statistical Package for Social Science (SPSS- 16).

\section{RESULTS:}

Most respondents were between age 50-59 years. Most being illiterate $82 \%$. Surprisingly only $18 \%$ were literate. Most of the in-laws had parity more than five, $61 \%$ (Table 1).

Table 1: Demographic variables $(N=100)$

\begin{tabular}{|ccc|}
\hline Variables & Percentage & \\
\hline Age (years) & & \\
$40-49$ & 34 & Mean $=52.33$ \\
$40-59$ & 20 & \\
$60-69$ & 7 & \\
\hline $70-79$ & 1 & \\
\hline $80-89$ & & \\
\hline Educational status & 82 & \\
\hline Illiterate & 18 & \\
\hline Literate & & Range $=1-13$ \\
\hline Number of children & 12 & Median $=5$ \\
\hline Up to two & 27 & \\
\hline 3-4 & 61 & \\
\hline five or more & & \\
\hline
\end{tabular}

With respect to educational status and awareness score, most of the illiterate had inadequate score $81.7 \%$ but $18.3 \%$ among the illiterate group had moderate awareness. And the In-laws who were literate, $50 \%$ of them had moderate awareness. The relationship was statistically significant (Table 2).

The relationship between parity of in-laws and awareness score was statistically insignificant ( $p$ $=0.58$ ). Most of them had only moderate awareness score although the parity was $<5,25.8 \%$. This is similar to those whose parity was $>5,21.1 \%$ (Table 3).
Table 2: Educational status and awareness of birth preparedness and complication readiness $(N=100)$

\begin{tabular}{cccc}
\hline \multicolumn{4}{c}{ Awareness score } \\
Educational status & Inadequate* $^{*}$ Moderate $^{\#}$ & $p$ \\
\hline Illiterate & $67(81.7 \%)$ & $15(18.3 \%)$ & 0.004 \\
Literate & $9(50 \%)$ & $9(50 \%)$ & \\
\hline
\end{tabular}

${ }^{*}$ Inadequate awareness score $=$ less than $50 \%$ score; ${ }^{*}$ Moderate awareness score $=$ score between $50 \%$ to $75 \%$

Table 3: Parity and awareness of birth preparedness and complication readiness $(N=100)$

\begin{tabular}{cccc}
\hline \multicolumn{4}{c}{ Awareness score } \\
Parity & Inadequate* $^{*}$ & Moderate $^{\#}$ & p \\
\hline Five or less & $46(74.2 \%)$ & $16(25.8 \%)$ & 0.58 \\
More than Five & $30(78.9 \%)$ & $8(21.1 \%)$ & \\
\hline
\end{tabular}

${ }^{*}$ Inadequate awareness score $=$ less than $50 \%$ score; ${ }^{*}$ Moderate awareness score $=$ score between 50\% to $75 \%$

\section{DISCUSSION:}

The level of knowledge of mother in law was assessed with the help of interview schedule for indepth interviews incorporating various components of birth preparedness and complication readiness. A total of 100 mother in laws were interviewed out of which $72 \%$ belonged to age group of $40-59$ years $(M=52.33, S D=8.96)$. Majority (82.0\%) mothers-inlaw were illiterate and respondents' children ranged from one to 13 with median number of children were being five.

Sixty-six percent were involved in practices of birth preparedness and complication readiness, among them $77.8 \%$ from literate mothers-in-laws. John and his friends conducted a study and stated that educational status and parity were the best predictor of awareness of the concept of birth preparedness ( $p=0.0029$ and 0.4433 , respectively). ${ }^{4}$ When an emergency occurs, in most cases it takes a woman and her family time to realize the seriousness of the situation. The majority of pregnant women and their families do not know how to recognize the signs of complications, nor do they know what to do and where to get help. ${ }^{5}$ A study conducted in Kenya among 394 women attending antenatal care on birth preparedness, knowledge of danger signs, preparations for delivery and emergencies indicted that $87.3 \%$ of the respondents were aware of their expected date of delivery but all respondents could not have a clear plan of what to do in case 
of an obstetric emergency and level of education positively influenced on birth preparedness. ${ }^{6}$ In the study, most of them $(81.7 \%)$ had inadequate awareness score on practice of birth preparedness and complication readiness. Significant association $(p=0.004)$ was found between literate and illiterate respondents on awareness about birth preparedness and complication readiness which was more similar with study done by Hiluf and Fantahun in Kenya where there was significant association of women's knowledge and practice on birth preparedness and complication readiness. Educated women had more practiced on birth preparedness and complication readiness. $^{7}$

In the study, 62\% mothers-in-law had equal or less than five numbers of children, among them 74.2 percent could have inadequate awareness score. A cross-sectional, multicentric descriptive study was carried out in Calabar and Biase local government areas of Cross River state, Nigeria state. Parity was a better predictor of knowledge of

\section{REFERENCES:}

1. WHO. "Reproductive health strategy". A framework for implementing the reproductive health strategies in the south East Asia region. WHO/SEARO, New Delhi. 2008.

2. Moren AC, Sangli DR, Rawling B, Yamego M, Baya B. "Birth preparedness for maternal health". J Health Popul Nutr. 2006;24:489-97.

3. Ministry of Health and Population (MOHP) [Nepal], New ERA, and Macro Interna_onal Inc. "Nepal Demographic and Health Survey 2006: maternal health (Birth Preparedness)". New ERA, MoHP USAID. 2007; 145.

4. John E. et al. "Awareness of Birth Preparedness and Complica_on Readiness in Southeastern Nigeria”. J Obstet Gynecol 2011; 56: 41.

5. USAID. "Saving Mothers' Lives: What works, a field guide severe vaginal bleeding as a key danger sign during pregnancy than educational level $(p<0.001$ and $p=$ 0.38 , respectively). ${ }^{4}$ But another study conducted by Addis Ababa University (College of health sciences) in Ababa, Ethiopia at 2011 found to be no association between parity and knowledge of danger signs during pregnancy8. Which was more likely to the finding of the study as priority had no association $(P=0.59)$ with awareness of birth preparedness and complication readiness.

\section{CONCLUSION:}

Inadequate awareness regarding birth preparedness and complication readiness was highly prevalent on illiterate mother-in-laws. An association between education status of mother-in-law and birth preparedness and complication readiness was statistically significant but not observable in parity of mother-in-laws.

for implementing best practices in safe motherhood". The White Ribbon Alliance for Safe Motherhood/India. 2005.

6. $\mathrm{Mu}_{\text {_ so }} \mathrm{SM}$, Qureshi Z, Kinuthia J. "Birth preparedness among antenatal clients at Kenya_a National Hospital, Kenya". East Afr Med J. 2008;85:275-83.

7. HilufM, Fantahun M. Birth Preparedness and Complication Readiness among women in Adigrat town, North Ethiopia. J Health Ethio. 2008;22:14-20.

8. Luchia A. Assessment of knowledge and practice on birth Preparedness and complication readiness among antenatal clients in selected health centers in addis Ababa, Ethiopia. An unpublished thesis Submitted to the School of Graduate Studies of Addis Ababa University. 2011. 